\title{
DEMOCRACIA E AS RECENTES REFORMAS DAS POLÍTICAS CURRICULARES NO CONTEXTO DA EDUCAÇÃO BÁSICA NO BRASIL
}

\author{
Maria Zuleide da Costa Pereira \\ Professora Titula do Departamento de Habilitações Pedagógicas atuando no Centro de Educação \\ da Universidade Federal da Paraíba e no Programa de Pós-graduação em Educação. E-mail: \\ mzul@uol.com.br \\ https://orcid.org/0000-0002-8980-9302 \\ Miriam Espindula \\ Doutoranda do Programa de Pós-graduação em Educação da Universidade Federal da Paraíba. E- \\ mail: mira.espindula@gmail.com \\ https://orcid.org/0000-0002-6506-9901

\section{Letícia Ramos} \\ Doutorando do Programa de Pós-graduação em Educação da Universidade Federal da Paraíba. E- \\ mail: leticiaramosufpb@gmail.com \\ https://orcid.org/0000-0002-3220-6439
}

\section{RESUMO}

O Brasil assim como inúmeros países da Europa, América Latina e do Norte, vem sendo eivado por uma onda crescente de regimes políticos neoliberais e neoconservadores, os quais têm propiciado uma ameaça constante à democracia mundial devido aos inúmeros retrocessos de direitos políticos e sociais. Nessa nova conjuntura política esses direitos dos cidadãos/ãs estão sendo negados, entre eles, o direito a uma educação pública e democrática. Ressalte-se que a reforma curricular proposta para a educação básica, segundo pesquisas (SOEK, 2017; ROCHA, 2016; ROCHA; PEREIRA, 2016, 2018), foi homologada no Brasil sem a participação dos protagonistas (professores/as) das escolas públicas. Os debates acerca dessas reformas curriculares se intensificaram e sob a égide de políticas neoliberais e neoconservadoras que propuseram algumas versões de propostas curriculares, constituem-se uma ameaça real à educação democrática no Brasil, não só pela pseudoparticipação dos docentes, mas também pela rapidez com que foram elaboradas e homologadas. Optamos por uma perspectiva teórico-metodológica pós-estrutural pautada nas teorizações de Mouffe (1996, 2003, 2007), sobre a democracia agonística; e, em Pereira e Albino (2015); Pereira e Lima (2012); Rocha e Pereira (2016, 2018); sobre as recentes reformas das políticas curriculares. Em síntese, nossa questão central é investigar, no contexto atual da educação básica no Brasil, se a democracia permeou o processo de tessituras de políticas curriculares garantindo de forma real a efetiva participação da sociedade civil através de suas diferentes instâncias político-científicas.

Palavras-chave: Educação Democrática. Políticas Curriculares. Educação Básica.

\section{DEMOCRACY AND RECENT REFORMS OF CURRICULAR POLICIES IN THE CONTEXT OF BASIC EDUCATION IN BRAZIL}

\begin{abstract}
Brazil, like many countries in Europe, Latin America and the North, has been plagued by a growing wave of neoliberal and neoconservative political regimes, which have provided a constant threat to world democracy due to countless setbacks in political and social rights . In this new political context these rights of citizens are being denied, among them, the right to a public and democratic education. It should be emphasized that the curricular reform
\end{abstract}


proposed for basic education, according to research (SOEK, 2017; ROCHA, 2016; ROCHA; PEREIRA, 2016, 2018) was approved in Brazil without the participation of the protagonists. The debates about these curricular reforms intensified and under the aegis of neoliberal and neo-conservative policies that proposed some versions of curricular proposals, constitute a real threat to democratic education in Brazil, not only because of the pseudo-participation of teachers, but also because of the rapidity with which were prepared and approved. We opted for a post-structural theoretical-methodological perspective based on the theorizations of Mouffe (1996, 2003, 2007), on agonistic democracy; and in Pereira and Albino (2015); Pereira and Lima (2012); Rocha and Pereira (2016, 2018); on recent curricular policy reforms. In short, our central question is to investigate, in the current context of basic education in Brazil, whether democracy permeated the process of curricular policy tessitures, guaranteeing in a real way the effective participation of civil society through its different political-scientific instances.

Keywords: Democratic Education. Curricular Policies. Basic education.

\section{DEMOCRACIA Y LAS RECIENTES REFORMAS DE LAS POLÍTICAS CURRICULARES EN EL CONTEXTO DE LA EDUCACIÓN BÁSICA EN BRASIL}

\section{RESUMEN}

Brasil, así como numerosos países de Europa, América Latina y el Norte, viene siendo eivado por una ola creciente de regímenes políticos neoliberales y neoconservadores, que han propiciado una amenaza constante a la democracia mundial debido a los numerosos retrocesos de derechos políticos y sociales. En esta nueva coyuntura política esos derechos de los ciudadanos / a están siendo negados, entre ellos, el derecho a una educación pública y democrática. En el marco de la reforma de la educación básica, según investigaciones (SOEK, 2017, ROCHA, 2016, ROCHA, PEREIRA, 2016, 2018), fue homologada en Brasil sin la participación de los protagonistas (profesores / as) de las escuelas públicas . Los debates sobre estas reformas curriculares se intensificaron y bajo la égida de políticas neoliberales y neoconservadoras que propusieron algunas versiones de propuestas curriculares, se constituyen una amenaza real a la educación democrática en Brasil, no sólo por la pseudoparticipación de los docentes, sino también por la rapidez con que fueron elaboradas y homologadas. Optamos por una perspectiva teórico-metodológica postestructural pautada en las teorizaciones de Mouffe (1996, 2003, 2007), sobre la democracia agonística; y en Pereira y Albino (2015); Pereira y Lima (2012); Roca y Pereira (2016, 2018); sobre las recientes reformas de las políticas curriculares. En síntesis, nuestra cuestión central es investigar, en el contexto actual de la educación básica en Brasil, si la democracia permeó el proceso de tesis de políticas curriculares garantizando de forma real la efectiva participación de la sociedad civil a través de sus diferentes instancias políticocientíficas.

Palabras clave: Educación Democrática. Políticas Curriculares. Educación básica.

\section{INTRODUÇÃO}

O objetivo deste texto é investigar, no contexto atual da educação básica no Brasil, se a democracia permeou o processo de tessituras de políticas curriculares garantindo de forma real a efetiva participação da sociedade civil através de suas diferentes instâncias 
político-científicas. Tal objetivo irá nos levar a considerações sobre a descentralização de um currículo hegemônico de padrões estadunidenses, tecendo possibilidades para a elaboração de um currículo que traz para seu seio as diferenças e a disseminação do poder como necessária para um currículo democrático pautado nos agonismos.

Há muito tempo as lutas agonistas por uma educação democrática no Brasil giram em torno da reorganização do cenário econômico, político e social, o qual promoveu a hegemonia das políticas neoliberais e neoconservadoras de direita que enaltecem aspectos lógicos desses contextos marcados por sentidos que expressam um modelo racionalista de organização dos mercados. A mercantilização, os padrões de qualidade, o desempenho, a competividade, meritocracia, competência vão semeando uma realidade que vem marcada por um movimento de resistência no âmbito das instâncias científico-acadêmicas e de parte significativa dos profissionais que atuam nas escolas de educação básica do Brasil. Para entender as raízes neoconservadoras dessas reformas educacionais percebemos ser indispensável, a priori, entender: O que é democracia? Como se caracterizam as sociedades democráticas? Como a democracia está sendo materializada no Brasil? De qual democracia estamos falando? Como o regime democrático do Brasil se reverbera no seu campo educacional?

Assim, para entendê-la melhor nos acostamos às teorizações pós-estruturalistas de Mouffe $(1996,2003,2007)$ que ao tratar da temática "Democracia, cidadania e a questão do pluralismo" em um de seus textos começa indagando: o que é uma sociedade democrática? Essa é a indagação cerne de nossos debates. Logo no início do texto, com vistas a buscar mais elementos de análise para compreender os contextos das sociedades democráticas atuais, entre elas, a sociedade brasileira e como ela encaminha o político nas políticas. Posteriormente, abordamos como a democracia se materializa no Brasil, visto que, nos últimos cinco anos, ela começou a dar sinais de vulnerabilidade. Nesse sentido, parece imprescindível tentar discorrer de qual democracia estamos falando e quais as suas influências no contexto da educação básica no Brasil.

\section{QUESTIONANDO O MODELO DEMOCRÁTICO DO BRASIL E SUGERINDO CAMINHOS PLURAIS}

Em se tratando da história política do Brasil após um regime ditatorial de 21 anos (1964-1985), o processo de redemocratização começou a ser efetivado em 1985, com a eleição de Tancredo Neves, via colégio eleitoral, em eleições indiretas. Com a sua morte 
súbita no mesmo ano, assumiu a presidência da república o vice-presidente Jose Sarney, para um mandato de 5 anos, até quando as eleições ocorressem.

No entanto, após as eleições de 1989, a história política do Brasil tem criado cenários preocupantes no que se refere à democracia no país. Esta aparenta complexa, mas não tão consolidada quanto gostaríamos que fosse, sobretudo, devido às rupturas políticas ocasionadas por dois impeachments. O primeiro ocorrido na década de 90 que destituiu do poder o presidente, à época, Fernando Collor de Mello. O segundo ocorrido recentemente, em 2016, com a presidenta Dilma Rousseff.

Essas rupturas políticas, sobretudo, a última, trouxeram maior vulnerabilidade à democracia de nosso país diante da corrupção em várias instâncias do poder. A sociedade política perdeu a credibilidade e o povo foi às ruas lutar por democracia. Portanto, entender quando se pode afirmar que uma sociedade é democrática são lições pertinentes e necessárias diante das tramas políticas autoritárias e manchadas pela corrupção generalizada no Brasil. Identificar nosso modelo de democracia é relevante para compreender as direções do político e da política que vão se materializando em nosso país. Em qual modelo político a política do Brasil se ancora?

Após a ditadura militar vivemos tempos de lutas para que a história não se repetisse, buscando sempre zelar pela manutenção da democracia, fortalecendo os princípios democráticos em diferentes esferas da sociedade: escolas, sindicatos, Universidades, Associação Nacional de Pós-Graduação e Pesquisa em Educação (ANPED), Associação Nacional de Política e Administração da Educação (ANPAE), Associação Nacional pela Formação dos Profissionais da Educação (ANFOPE), entre tantas outras instituições.

Porém, há outra maneira de arruinar uma democracia. É menos dramática, mas igualmente destrutiva. Democracias podem morrer não nas mãos de generais, mas de líderes eleitos - presidentes ou primeirosministros que subvertem o próprio processo que os levou ao poder. Alguns desses líderes desmantelam a democracia rapidamente, como fez Hitler na sequência do incêndio do Reichstag em 1933 na Alemanha. Com mais frequência, porém, as democracias decaem aos poucos, em etapas que mal chegam a ser visíveis (LEVITSKY; ZIBLATT, 2018, p. $15)$.

Vimos tal processo acontecer no Brasil, numa reviravolta marcada nas eleições de 2018, quando o Brasil elegeu para Chefe do Executivo o maior representante político do 
"neoultraconservadorismo" brasileiro, Jair Bolsonaro, notável em criar polêmicas e discursos moralistas que contrastam com algumas de suas ações.

Assistimos a uma mudança abrupta na configuração da democracia, em que os políticos começaram a tratar seus rivais como inimigos, utilizaram de várias estratégias para a intimidação, a imprensa livre passou a ser desacreditada e uma onda de fake news, nas redes sociais, desestruturou discursos, construiu pautas que reforçaram preconceitos, defendeu a retomada dos "tempos áureos" dos valores tradicionais e militarizados, também confundiu os eleitores com notícias falsas sobre corrupção. Foi assim que um homem que foi deputado federal de 1991 a 2018, sem nenhum projeto aprovado, tornou-se presidente e agora, com posturas neoconservadoras de direita, tenta ultrajar a democracia no Brasil.

Sobre como as democracias são ultrajadas, morrem e desaparecem, Levitsky e Ziblatt, (2018, p. 17) em debates atuais afirmam que "[...] desde o final da Guerra Fria, a maior parte dos colapsos democráticos não foi causada por generais e soldados, mas pelos próprios governos eleitos. Como Chávez na Venezuela, [...]”. Pensamos que os modelos democráticos que aí estão não estão garantindo a representatividade da sociedade civil. Passamos, no Brasil, por esse problema quanto à representatividade. $\mathrm{O}$ então presidente, Jair Bolsonaro (PSL), foi eleito com apenas 39,5\% dos votos, quando 60,5\% dos eleitores votaram em branco, nulo, no oponente Fernando Haddad (PT). Como afirmar que um governo que agregou menos de 50\% dos eleitores é capaz de governar de forma a instituir uma sensação de representatividade na população brasileira? Então, qual seria o modelo de democracia que defenderíamos?

\section{Por uma democracia agonística: conflito, a paixão e o político}

A teórica Chantal Mouffe desenvolve seus escritos na perspectiva de reescrever princípios fundamentais da democracia de forma a incluir dentro desse sistema o "conflito, a paixão e o político" (MOUFFE, 1996, p. 165). Para tal, faz crítica à teoria democrática liberal, adotada no Brasil, ressaltando a tentativa de homogeneização que essa perspectiva traz ao pluralismo político, bem como limitações ao campo da representatividade e legitimidade. Faz suas incursões através do campo da filosofia política para trazer suas críticas e contribuições para a construção de um novo modelo de democracia radical ou pluralista.

Na obra, O regresso do político, Mouffe (1996) traça críticas às democracias liberais, que defendem um "modelo" único a ser seguido pelo restante do mundo. Para a 
autora, tal modelo democrático tem faces machistas, eurocêntrico e individualista característico do pensamento liberal.

Destarte, a evidência é que o pensamento liberal considera como modelo ideal aquele que tem em seus alicerces a imposição de valores, sendo esse sugerido universalmente, como se fosse possível estabelecermos um modelo único para todos os países.

Assim, Mouffe (1996) destaca que o ideário universalista desencadeia uma "agonia" da política, que nada mais é do que a incapacidade de reconhecer a diversidade e as diferenças como elementos fulcrais para o desenvolvimento de modelos plurais de sociedade e o aperfeiçoamento constante da democracia. Neste sentido, a autora compreende a diversidade e a diferença como uma característica própria e nuclear da democracia.

Mediante a crise vivenciada pela democracia liberal, a autora defende a urgência de elaborarmos outras formas para além dos moldes representativos e do instrumentalismo da política que esse modelo institui: “[...] Está claro que ao desencorajarem o envolvimento ativo dos cidadãos no funcionamento da unidade política e ao encorajarem a privatização da vida, eles não asseguram a estabilidade que anunciaram [...]" (MOUFFE, 1996, p. 172).

Mouffe (1996, p. 172) pontua como necessária a retomada da participação política dos cidadãos. Para ela o "[...] crescimento de várias religiões, bem como de fundamentalismos morais e étnicos, é a consequência direta do déficit democrático que caracteriza a maior parte das sociedades liberal-democráticas [...]”. Entretanto, a participação, não necessariamente, culminará numa consolidação de consensos racionais, pelo contrário, irá colocar em evidência os conflitos que são naturais da vida em sociedade.

Nesses termos é necessário reconhecer a característica inesgotável do antagonismo como elemento inerente do pluralismo das relações humanas. Assim, Mouffe (1996, p. 173) propõe um modelo "agonístico" de democracia - a disputa de adversários pela significação dos valores e princípios -, “[...] capaz de apreender a natureza do político. Isso requer o desenvolvimento de uma abordagem que inscreve a questão do poder e do antagonismo em seu próprio centro".

A democracia de Mouffe (1996, p. 165) requer um conceito do político que seja do âmbito de uma proposta agonística de democracia, renunciando-se com a polarização econômico-ética dos pensadores liberais, do entendimento do político “[...] à naturalização das fronteiras da democracia e dos embates entre seus atores". Assim, os inimigos 
assumem o papel de adversários disputando a significação dos valores e princípios éticospolíticos.

Neste momento é importante diferenciar "o político" e "a política", como faz Mouffe (2003, p. 15). O entendimento do "político" de acordo com a autora dá relevo ao antagonismo que é "[...] inerente a todas as sociedades humanas, antagonismo que pode assumir formas muito diferentes e emergir em relações sociais diversas".

Por outro lado, a compreensão de "política" vincula-se "[...] ao conjunto de práticas, discursos e instituições que procuram estabelecer uma certa ordem e organizar a coexistência humana em condições que são sempre potencialmente conflituosas, porque afetadas pela dimensão do "político"' (MOUFFE, 2003, p. 15).

Ainda, pode-se afirmar que:

[...] pelo racionalismo, pelo individualismo e pelo universalismo abstrato, este tipo de teoria deve necessariamente permanecer cego à natureza do político e à inerradicabilidade do antagonismo. Na verdade, o termo "político" está cada vez mais presente na filosofia liberal, mas o domínio do político é sempre tratado por uma abordagem individualista e racionalista que o reduz ou ao econômico ou ao ético. Como consequência, a dinâmica da constituição dos sujeitos coletivos e o papel crucial desempenhado pelas paixões e antagonismos neste campo não podem ser apreendidos. Aí reside a explicação para a impotência da maioria dos liberais para oferecer respostas adequadas aos problemas em curso (MOUFFE, 2003, p. 12).

Nessa direção o entendimento de democracia defendido pela autora rompe com a ilusão do consenso e os apelos ao "antipolítico". Estes movimentos "antipolíticos" e/ou oportunistas - avessos aos processos democráticos pluralistas - ocupam-se dos lugares vazios movendo frentes compostas por identidades antidemocráticas, que apresentam riscos e se propagam utilizando os lugares desocupados deixados pelo "político", esses movimentos são avessos aos processos democráticos pluralistas.

Segundo Mouffe (1996, p. 173), “[...], a prática política não pode ser entendida como simplesmente representando os interesses de identidades pré-constituídas, mas como constituindo essas próprias identidades em um terreno precário e sempre vulnerável”.

Diferentemente do pensamento liberal, a questão primordial para a política democrática é a constituição de formas de poder compatíveis com os valores democráticos, para eliminar a lacuna entre poder e legitimidade. 
Tendo as questões do antagonismo e do poder como epicentro da democracia, Mouffe (1996) advoga pelas bases teóricas desenvolvidas na obra Hegemonia e estratégia socialista: por uma política democrática e radical, de sua autoria em parceria com Ernesto Laclau, em que a tese é que a sociedade é constituída por atos de poder. Isso significa que: “[...] se aceitamos que as relações de poder são constitutivas do social, então a questão principal da política democrática não é como eliminar o poder, mas como constituir formas de poder compatíveis com valores democráticos [..]” (MOUFFE, 1996, p. 14).

Tal pensamento é uma superação da ideia de que quanto menos "poder" uma sociedade possui, mais democrática ela é, por ter menos conflitos, possibilitando a construção de um consenso, de um padrão. Deste modo, o pluralismo se apresenta e se torna parte indissociável do pensamento democrático agonístico reconhecendo as diferenças como um ponto nodal da teorização de Mouffe sobre o "pluralismo agonístico", cuja peculiaridade é reconhecer e prestigiar a dimensão conflitual da vida em sociedade.

No pensamento de Mouffe (1996, p. 174):

Vislumbrada a partir da óptica do "pluralismo agonístico", o propósito da política democrática é construir o "eles" de tal modo que não sejam percebidos como inimigos a serem destruídos, mas como adversários, ou seja, pessoas cujas ideias são combatidas, mas cujo direito de defender tais ideias não é colocado em questão.

[...] Um adversário é um inimigo, mas um inimigo legítimo, com quem temos alguma base comum, em virtude de termos uma adesão compartilhada aos princípios ético-políticos da democracia liberal: liberdade e igualdade.

[...] De fato, dado o pluralismo inerradicável de valores, não há solução racional para o conflito - daí sua dimensão antagonística.

A confrontação agonística é a condição primeira para a existência da democracia. Logo, é possível adversários deixarem de discordar, entretanto isso não resulta na eliminação do antagonismo entre eles. Ademais, existe a possibilidade da formalização de pactos/acordos. Todavia, pactos/acordos são temporários e causam interrupções no confronto entre adversários.

Em outros termos,

Introduzir a categoria do adversário requer tornar complexa a noção de antagonismo e a distinção de duas formas diferentes mediante as quais ela pode emergir: o antagonismo propriamente dito e o agonismo. $\mathrm{O}$ antagonismo é a luta entre inimigos, enquanto o agonismo representa a luta entre adversários [...] o propósito da política democrática é 
transformar o antagonismo em agonismo. [...] para o "pluralismo agonístico", a tarefa primordial da política democrática não é eliminar as paixões da esfera do público, de modo a tornar possível um consenso racional, mas mobilizar tais paixões em prol dos desígnios democráticos.

O que a autora destaca acima seria denominado de consenso conflituoso. Nunca eliminaremos o confronto agonístico dos adversários na cena política, pois dado confronto é indissociável da sociedade, tornando-se utópica a ideia de um consenso racional.

Por fim, Mouffe (1996) revela a necessidade de nos mantermos atentos e considerarmos a fragilidade da democracia, fazendo uma defesa constante, intransigente por sua manutenção. Para isso, é necessário que o processo democrático seja saudável, evitando colocar em risco a democracia. Paradoxalmente, é imprescindível a existência do conflito, da diferença, do antagonismo, dos adversários, pois esses elementos pressupõem a existência da democracia e o seu processo de aperfeiçoamento, onde a pluralidade das diferenças culturais é defendida e abrigada.

A partir dessas ideias, pretendemos, no tópico a seguir, gerar pistas para olhares plurais do pensar e fazer políticas curriculares, gerando possibilidades outras na pesquisa sobre a temática e reconhecendo a necessidade da consolidação da participação popular, defendendo a necessidade de reformas de políticas curriculares mais agonísticas, que tragam para dentro da teorização do campo educacional brasileiro perspectiva plural e radical.

Para que isso possa de fato acontecer se faz necessário estar sempre questionando o caráter democrático das reformas curriculares no campo educacional brasileiro em duas instâncias: na política e no político, ou seja, nos textos da política de currículo e nos representantes que são responsáveis por selecionar as demandas educacionais a serem incluídas nesses textos. E sobre o caráter democrático das recentes reformas curriculares que ocorreram no Brasil que enfocaremos a seguir.

\section{AS REFORMAS CURRICULARES DA EDUCAÇÃO BÁSICA NO BRASIL: ORIGENS, DESAFIOS, RETROCESSOS E/OU AVANÇOS}

A educação como direito de todos foi somente recentemente garantida no Brasil, a partir de dois instrumentos legais: a Constituição Federal de 1998 e a Lei de Diretrizes e Bases da Educação (LDB 9394/96). A “educação, direito de todos e dever do Estado e da família, será promovida e incentivada com a colaboração da sociedade, visando ao pleno desenvolvimento da pessoa, seu preparo para o exercício da cidadania e sua qualificação 
para o trabalho" (CF/88, art.205). O que significa assegurar, entre outras questões, a igualdade de condições para o acesso à escola, o pluralismo de ideias, a gratuidade e a gestão democrática do ensino público, sendo "o acesso ao ensino obrigatório e gratuito um direito público subjetivo" (CF/88, art. 208, §1º) endossado pela (LDB 9394/96, art. $5^{\circ}$ ) que reitera esse direito público subjetivo como um dever inalienável do Estado.

No entanto, para que esse consenso fosse estabelecido foi necessário superar a concepção elitista de educação do século XIX, a concepção seletiva do século XX e alcançar os avanços no campo do direito à educação pública, democrática, inclusiva e de qualidade. Princípios que estão sendo violados ao ser negado o direito às diferenças, à diversidade e ao dissenso como maneiras de construir e aperfeiçoar a democracia e o exercício democrático dos indivíduos na definição das políticas públicas educacionais brasileiras desde que forças conservadoras recentemente ascenderam ao poder.

Dito isso, torna-se imprescindível questionar o caráter democrático dessas reformas curriculares em suas duas dimensões: na política e no político (Mouffe, 1996). De forma similar, nos textos da política das reformas educacionais e nos representantes que são responsáveis por selecionar as demandas educacionais a serem incluídas nesses textos. Para adentrar na esfera da política, lembramos Pereira (2009, p. 117-118) quando ela afirma que o debate/produção das políticas é “[...] como redes de significação (múltiplos sentidos), por favorecer incorporações importantes vivenciadas nos contextos atuais. Algumas dessas questões se traduzem em análises sobre cultura, gênero, raça/etnia, religião, geração, orientação sexual etc.”.

E, assim, podemos começar pela concepção de educação básica, que traz em si um significado novo, amplo do ponto de vista da legislação educacional, balizado pela Constituição de 1988 e sistematizado pela LDB 9394/96 em dois de seus artigos. No art. 21, a definição do conceito da educação básica como um nível da educação nacional que reúne articuladamente as três etapas de ensino: o infantil, o fundamental e o médio. E como um jogo de linguagem, sua interpretação pode ser de terminalidade impelindo o jovem para o mercado de trabalho ou pode ser de prosseguimento dos estudos, dado que etimologicamente base sinaliza etapas conjugadas sob um só todo e provém do grego básis, e ós que significa, entre outros, pôr em marcha, avançar.

Nesse contexto, o processo de construção e debate dessa conceituação de educação básica deu-se no período pós Constituição de 1998, inicialmente participativo, no qual houve a disputa dos adversários pela significação dos valores e princípios, como resultado 
de mobilização e articulação dos educadores e educadoras, entidades sindicais, acadêmicas e estudantis representados pelo Fórum em Defesa da Educação Pública na Constituinte que, enfim, conseguiram projetar concepções de educação possíveis em meio ao embate entre as forças em disputa, mas coerentes com o momento de redemocratização.

Em busca da normatização e objetivação da concepção da educação básica defendida pelo Fórum em Defesa da Educação Pública, a LDB 9394/96, em seu art. 22, estabelece como fins da educação básica "desenvolver o educando, assegurar-lhe a formação comum indispensável para o exercício da cidadania e fornecer-lhe meios para progredir no trabalho e em estudos posteriores".

Desse modo, tais significações sobre educação assumem alguns aspectos: i) confere à terminologia educação básica o caráter de originalidade/inovação, ii) reconhece a importância da educação escolar para a vida em suas diferentes fases, iii) desvincula a qualificação para o trabalho como finalidade dessa etapa da educação e, iv) apresenta a continuidade dos estudos e o trabalho como corpo de uma educação cidadã que rompe com a visão dualista entre cidadania e trabalho.

E, assim, aproxima-se da afirmação do direito à educação para todos quando amplia a escolarização gratuita e obrigatória para as crianças e jovens dos 04 aos 17 anos, ou seja, da pré-escola ao ensino médio, antes, restrita ao ensino fundamental dos 07 aos 14 anos.

Porém, as disputas pela significação das políticas não foram fáceis. Destacamos o embate das forças progressistas com a instância governamental de Fernando Henrique Cardoso que apresentou uma política educacional que seguia os ditames da orientação neoliberal e que interferiu diretamente nos avanços incorporados ao projeto da LDB. (ANPEd, 2007). O confronto com os lobbies dos privatistas radicalizando o duelo entre o público e o privado, com a posição neoliberal prevalecente, o que abriu amplos espaços para a iniciativa privada no projeto que deu origem à Lei 9394/96. Fatos que caracterizaram momentos de autoritarismo na condução (período para análise e votação no Congresso) do projeto em questão.

$\mathrm{Na}$ esteira da LDB, o Ministério da Educação (MEC) fomentou os Planos Nacionais de Educação (PNE 2001-2011 e 2014-2024) com metas e estratégias e as Diretrizes Curriculares Nacionais (DCNs) cuja origem na LDB apontam princípios que norteiam as políticas e reformas curriculares desde então. As narrativas desses textos e de outros deles decorrentes, tais como os Parâmetros Curriculares (PCNs) e, atualmente, a Base Nacional Comum (BNCC), dão visibilidade à influência das agências externas na 
educação brasileira, a partir dos anos 90, cuja nova agenda para a educação básica foi montada na Conferência Mundial sobre Educação para Todos, realizada em Jomtien (1990), na Tailândia

Em Jomtien, foi aprovada a Declaração Mundial sobre Educação para Todos, documento que aprofunda as intenções, por parte de seus financiadores e planejadores, de implantar uma reforma no campo educacional sobre as bases de um novo projeto de formação humana, de orientação neoliberal de educação, sobretudo, no que se refere à não democratização das reformas do ensino médio e à instituição da hegemonia do racionalismo. O que de fato corresponde a uma perspectiva de educação seletiva e minimalista para os que provavelmente vão exercer trabalho simples durante toda a vida, priorizando a educação básica e se restringindo às "necessidades básicas de aprendizagem".

Pode-se dizer que a migração dessa Declaração nos anos 2000 para a criação local, em 2006, da organização empresarial "Todos pela Educação", intensificou a tendência à apropriação privada do saber sistematizado na escola pública brasileira, sob o argumento de que as políticas educacionais desenvolvidas no país até então comprometiam os interesses empresariais, dada a baixa "qualidade" apresentada. Sendo assim, fazia-se necessário o estabelecimento de "competências básicas", metas de desempenho por meio do Índice de Desenvolvimento da Educação Básica (IDEB) e instrumentos centralizados de avaliação, dentre outros, baseados nos princípios da privatização, divisão técnica do trabalho educativo, responsabilização pelo desempenho dos estudantes nas avaliações externas, o patamar minimalista de formação para as novas gerações de trabalhadores (PINA, 2016), e isso culminou na Reforma do Ensino Médio.

Aliás, essa foi uma das reformas que caminhou na contramão do que defende Mouffe (1996, 2003, 1996), pois não contou com a participação popular na sua elaboração. Muito pelo contrário, gerou muitos protestos e ocupação de escolas por estudantes de todo o país, além de cartas abertas de entidades acadêmicas, científicas e de movimentos sociais. Formatada num momento de crise democrática do Brasil - o governo Michel Temer - foi enviada ao Congresso Nacional como Medida Provisória (MP) n n 746/2016, e se converteu na Lei ${ }^{\circ}$ 13.415/2017, que alterou a Lei de Diretrizes e Bases da Educação Nacional (LDB no 9394/96) e a Lei do Fundo de Manutenção e Desenvolvimento da Educação Básica e de Valorização dos Profissionais da Educação (FUNDEB nº 11.494). 
Cabe salientar que o Governo de Michel Temer marca a construção de pacotes para a educação e o desmonte da participação popular na construção das políticas. Tivemos o desmonte de vários espaços representativos de discussão sobre o campo do político entre eles a substituição dos Conselheiros do Conselho Nacional de Educação que tinham sido indicados pelos movimentos populares e trabalhistas de várias instituições do país, bem como o fim da Conferência Nacional de Educação, entre outros espaços. Todo esse esforço em busca de reduzir o pluralismo de ideias e a centralização do poder em um único grupo ideológico, o que levou a movimentos por todo o país.

Todavia, não de forma isolada tais demandas foram se apresentando para a nova democracia que se estabelecia no Brasil. Ao entendermos o currículo como redes de significações discursivas, isso pauta para o campo do político uma necessidade de compreender a sua formatação através de uma rede de interlocutores que vão tecendo caminhos e escolhas a serem pautadas em determinados momentos, ou seja, como coloca Mouffe (2003), para um poder se tonar hegemônico, é necessário que as demandas que um grupo defende se tornem representativas para um coletivo maior.

Assim, esse processo se dá em sintonia com a Cúpula de Dakar (UNESCO, 2000) realizada em Senegal, a qual defendia que "nenhum país pode aspirar desenvolver-se em uma economia globalizada sem que certa proporção de sua força de trabalho tenha completado o ensino médio" (UNESCO, 2000, p. 47). Todavia, é pertinente indagar de qual ensino médio está se falando. Sob qual contexto ele está sendo gerado? Sob a inspiração de Apple (2003), pode-se inferir que da forma como está posta, essa reforma reforça o "alinhamento à tendência internacional de transformar a educação em mercadoria, focando a formação para o trabalho e as necessidades do mundo capitalista, como ingredientes principais na elaboração de um currículo subserviente às demandas do mercado" (APPLE, 2003).

Mouffe (1996, 2003, 1996) já nos alertava sobre o espaço vazio e a capacidade que grupos "antepolíticos" têm de apropriar-se desses lugares que se constituem no campo político. Prova disso é a aliança entre instituições privadas, que deram fôlego à Reforma do Ensino Médio, instituindo novas formas de organização do trabalho produtivo materializadas na Lei ${ }^{\circ}$ 13.467/2017, que alterou a Consolidação das Leis do Trabalho (CLT). Freitas (2018 apud AZEVEDO; REIS, 2018), aponta que 
em vários países onde essa política educacional foi implantada, inclusive nos Estados Unidos, não se observou melhoria nos níveis de educação que pudesse ser atribuída a ela. No entanto, floresceram tanto a indústria educacional como a privatização da educação. A Nova Zelândia está eliminando a sua BNCC, pois considera que ela foi implantada por uma decisão ideológica e não tem fundamentação empírica.

As experiências supracitadas representam uma das críticas de Mouffe (1996) às respostas imediatistas e conservadoras dadas aos problemas sociais respaldadas ainda na democracia liberal centrada na dualidade economia-ética, negando inclusive o fracasso de vivências de outrem, sem nenhuma repercussão na reforma, pelo contrário, enveredando por uma racionalidade normativa e nada mais, pondo em risco a nossa democracia (MOUFFE, 1996).

Nesse sentido, arriscando inclusive o direito inalienável à educação de qualidade do jovem brasileiro, uma vez que os desafios dessa etapa de ensino no contexto da educação básica estão postos, basta observar os dados do INEP/MEC (BRASIL, 2018), pelo qual o número de matrículas de jovens vem declinando ano a ano, passando de 7,9 milhões em 2017 para 7,7 milhões em 2018. Segundo essas instituições, essa tendência de queda se deve a alguns fatores, dentre eles, às altas taxas de evasão e da migração de estudantes para a Educação de Jovens e Adultos (EJA) (BRASIL, 2018). Ademais, uma pesquisa realizada pelo Movimento Todos Pela Educação (2017) demonstra que 39\% dos estudantes de ensino médio brasileiro afirmam que a situação financeira é a principal dificuldade para concluir os estudos e 13,6\% dizem ter problemas para conciliar o trabalho com a escola.

Tais realidades sequer foram consideradas no processo de formulação dessa reforma, pois, desde 2017, normativas têm sido criadas com o intuito de realizar mudanças no ensino médio. A primeira delas foi a Lei $\mathrm{n}^{\circ} 13.415 / 2017$, que propôs o rearranjo do ensino médio em cinco itinerários formativos - linguagens e suas tecnologias, matemática e suas tecnologias, ciências da natureza e suas tecnologias, ciências humanas e sociais e aplicadas e formação técnica e profissional - sem, contudo, detalhar como isso seria feito. A segunda foi a Resolução no 4, de 17 de dezembro de 2018, que instituiu a Base Nacional Comum Curricular do Ensino Médio (BNCCEM), como etapa final da educação básica, na qual estabelece o que os estudantes têm o direito de aprender nas escolas de qualquer parte do país nesse novo arranjo curricular.

É oportuno lembrar que a reforma do ensino médio acarreta profundas alterações em sua organização curricular. O novo texto do Artigo 36 da LDB 9394/96 traz uma nova 
concepção de itinerário formativo em relação à Resolução CNE/CEB nº 6/2012, que define Diretrizes Curriculares Nacionais para a Educação Profissional Técnica de Nível Médio.

Um dos maiores retrocessos da reforma é a determinação pela BNCCEM do currículo composto por uma Base Nacional Comum que corresponde a $60 \%$ do total da carga horária prevista para essa etapa de ensino e cinco Itinerários Formativos compostos pelos $40 \%$ restantes da carga horária total. A Base será formada por disciplinas a serem cursadas obrigatoriamente pelos estudantes, com ênfase em língua portuguesa e matemática e os Itinerários Formativos que serão escolhidos pelos alunos dentre as opções oferecidas pela escola com base nos conteúdos das áreas de linguagens, matemática, ciências da natureza, ciências humanas e formação técnica e profissional, já mencionadas.

Dentre as determinações da BNCCEM, as escolas terão a obrigatoriedade de oferecer apenas um Itinerário Formativo por ano letivo, podendo ministrar até dois, um por semestre, conforme escolha do aluno. E então se estabelece uma dualidade. As escolhas dos jovens que logo cedo precisam se inserir no mercado de trabalho se direcionam para os Itinerários de formação para o ensino técnico e profissional, ficando os demais, tantos quantos forem ofertados pela escola, para os jovens que podem se dedicar, exclusivamente, aos estudos. Ademais, nesse formato de currículo, a BNCCEM garante que o conteúdo historicamente produzido pela humanidade será ministrado para os filhos ricos da sociedade que em suas escolas privadas e/ou em outras de excelência permanecerão tendo a oferta plena dos conteúdos.

É oportuno também considerar que a perspectiva de ensino profissionalizante da reforma mediante os Itinerários Formativos para além de tornar a dinâmica do currículo mais flexível e aberta, pode ser considerada uma tentativa de alinhar a escola ao "mundo do trabalho e torná-la menos amparada em disciplinas científicas e filosóficas (AZEVEDO; REIS, 2018, p. 69-75), e, por que não dizer, fundada em uma perspectiva ampla de formação vinculada à democracia.

\section{CONSIDERAÇÕES PROVISÓRIAS}

Nestas quatro últimas décadas houve uma mudança expressiva no desenho educacional do país. Tal reordenamento teve e tem como base reformas na legislação da educação que, em alguns momentos deste percurso, oscilou entre políticas mais ou menos democráticas. A Educação Básica no país, com as mudanças ocorridas a partir da última década do século anterior, tonou-se foco das políticas educacionais e curriculares. 
Questiona-se a partir de então a sua objetividade no que se refere à formação humana e ao atendimento das demandas do mercado. O novo realinhamento do capital, que se configura já no final do século anterior em nosso país, provoca alteração nas proposições e objetivos nos vários campos da formação humana, modificando as relações e percepções sobre essa formação.

A partir de 2014, com a proposta de elaboração de uma Base Nacional Comum Curricular (BNCC), os debates sobre os objetivos da educação e seu controle via avaliação nacional obtiveram grande destaque no cenário político, social, econômico e cultural brasileiro. As mudanças no campo educacional no país estiveram pautadas em articulações políticas, fundamentadas num modelo de democracia típico e singular, ou seja, uma democracia liberal. Esse modelo prioriza os fatores econômicos e seus impactos, adentrando os âmbitos sociais e culturais que, segundo tal percepção, precisam ser devidamente explorados.

As características desse modelo tecem todas as relações entre os políticos e as políticas desenvolvidas no país, com margem para atitudes de resistência por parte de teóricos do campo educacional. As reflexões mais incisivas e críticas sobre tal modelo são elaboradas por Mouffe (1996, 2003, 2007), que apresenta um modelo alternativo de democracia, pautado no agonismo.

Referendados em Mouffe (1996, 2003, 2007) percebemos algumas limitações do modelo liberal e, quando das análises sobre democracia, educação, políticas para a escola pública, observamos que as reformas educacionais e curriculares, particularmente as mais recentes, foram tecidas, na perspectiva de homogeneização numa tentativa de apagar as diferenças para reduzir a multiplicidade de poderes a um que instituiria o modelo ideal de sociedade. Por isso, a ideia de uma BNCC tomou força com o discurso de igualdade de direitos à aprendizagem, instituindo conteúdos mínimos que desrespeitam a pluralidade nacional. Isso, articulado com acordos internacionais e do realinhamento político econômico.

Para Mouffe (2003) este modelo democrático hegemônico pretende uma racionalidade, individualidade e universalidade que destoa das características econômicas, sociais e culturais do atual cenário social. A diversidade e as diferenças que estão na base de constituição das sociedades são percebidas como fatores a serem erradicados por meio do consenso pautado em valores morais, religiosos e éticos sedimentados. Este modelo 
pretende o retorno a tais valores e à invisibilização da diversidade e da diferença. Desconfigura a democracia enquanto direito à diferença.

Este fato nos impõe uma reflexão sobre as implicações deste movimento para as sociedades ditas democráticas. Sob quais características democráticas este movimento liberal neoconservador se pauta? Estamos na iminência de uma crise de democracia? As indagações suscitam uma profunda análise do campo democrático. Impelem-nos a questionar sobre os princípios da democracia que estão a fundamentar as ações de governos que se declaram democráticos e agem de forma uníssona.

No que concerne às políticas para o campo da educação se caracterizam pela pretensão à homogeneização da escola, dos professores, dos alunos, dos processos educativos e das realidades díspares do nosso país. No que concerne à Educação Básica, tem enfrentado inúmeros desafios, retrocessos e, também, limitados avanços. Na letra da lei, observa-se a inserção de demandas sociais advindas dos movimentos e de suas respectivas reivindicações, as quais caracterizam um dado momento histórico de governos recentes. Contudo, em muitos casos, a realidade ventila informações contraditórias. Basta realizar visita a alguma escola pública brasileira com um olhar mais apurado que você identifica distorções no que se refere à letra da lei e à realidade vivenciada no cotidiano.

Numa democracia radical, pretendida por Mouffe (2003), as proposições de alteração na legislação educacional seriam articuladas com os docentes, com a equipe de gestão escolar, com os políticos e com os estudiosos (nas diversas áreas de saber do campo). As divergências seriam concebidas como importantes para reflexão sobre a melhor forma de pensar/ e ou atuar, desnaturalizando, assim, a falsa percepção de que uma sociedade democrática se faz no consenso, na harmonia e na pacificação. Os atores envolvidos estariam num campo aberto à negociação com vista a atender da melhor maneira aos objetivos da educação.

Neste modelo, a diferença e os diferentes seriam concebidos como parte indissociável do movimento democrático plural. A dimensão do conflito seria ponto central nesta abordagem, presente a partir de visões plurais ancoradas em uma relação agonística entre adversários e não entre inimigos (MOUFFE, 1996, 2003, 2007). Entretanto, ainda não avançamos o suficiente para vislumbrar tal modelo. $\mathrm{O}$ que nos cabe neste momento, em que nossa democracia apresenta vulnerabilidade é estarmos atentos e resilientes na luta para mantê-la diante da voracidade com que o modelo liberal vem se ampliando no Brasil e no mundo. 
Ainda, fomos buscar em Mouffe (2003) a compreensão do que é uma sociedade democrática e, logo desnaturalizamos a concepção de que uma sociedade democrática se faz no consenso, na harmonia e na pacificação. Para a autora, a ideia de uma sociedade democrática se tece através de atitudes agnósticas, ou seja, de lutas, de negociações, de tensões e de conflitos que são imprescindíveis para a sua materialização. Para ela seria um equívoco entender uma sociedade democrática onde "os antagonismos foram erradicados e onde o modelo adversarial de política se tornou obsoleto".

Assim, para que as sociedades atuais sejam consideradas democráticas os conflitos deverão estar presentes a partir de visões plurais ancoradas em uma relação agonística entre adversários e não num binarismo amigos e inimigos. Por essa razão Mouffe (2003) defende um modelo de democracia radical nominada de "pluralismo agonístico". Sem dúvida nenhuma é modelo de sociedade democrática inovador que requer uma mudança de opção para pensar o político e fazer uma ação política que se contraponha ao avanço dos regimes conservadores de direita no mundo, sobretudo, no Brasil.

\section{REFERÊNCIAS}

APPLE. Michael W. Educação à Direita: mercados, padrões, Deus e desigualdades. São Paulo: Cortez, 2003.

Perspectivas Críticas: como pensamos sobre movimentos contra-hegemônicos e como participamos deles? In: PEREIRA, M. Z. da Costa; LIMA, Idelsuite de S. (org.). Currículo e políticas educacionais em debate. Campinas, SP: Editora Alínea, 2012. p. 17 43.

AZEVEDO, José Clovis de; REIS, Jonas Tarcísio. Políticas educacionais no Brasil pósGolpe. Porto Alegre: Editora Universitária, 2018.

BRASIL. Constituição da República Federativa do Brasil, de 05 de outubro de 1988. Constituição Federal. 8. ed. Porto Alegre: Verbo Jurídico, 2007.

Instituto Nacional de Estudos e Pesquisas Educacionais Anísio Teixeira. Relatório do $2^{\circ}$ Ciclo de Monitoramento das Metas do Plano Nacional de Educação 2018. Brasília, DF: INEP/MEC, 2018.

. Lei $n^{\circ}$ 9. 394, de 20 de dezembro de 1996. Estabelece as diretrizes e bases da
nacional. <http://www.planalto.gov.br/ccivil_03/Leis/L9394.htm>. Acesso em: 08 mar. 2019.

Ministério da Educação. Secretaria da Educação Básica. Fundamentos pedagógicos e estrutura geral da BNCC. Brasília, DF, 2017. Disponível em: <http://portal.mec.gov.br>. Acesso em: jan. 2019. 
ANPED - Associação Nacional de Pós-Graduação e Pesquisa em Educação, 2014. Retratos da Escola, Escola de Formação da Confederação Nacional dos Trabalhadores em Educação (Esforce), v. 10, n. 19, jul./dez. 2016. - Brasília: CNTE, 2007.

LACLAU, Ernesto; MOUFFE, Chantal. Hegemonia y Estratégia Socialista. Hacia una radicalización de la democracia. Madrid: Siglo XXI, 1987.

LEVITSKY, Steven; ZIBLATT, Daniel. Como as democracias morrem. Rio de Janeiro: Zahar, 2018.

MOUFFE, Chantal. Democracia, cidadania e a questão do pluralismo. Política \& Sociedade, Florianópolis, v. 1, n. 3, p. 11-26, out. 2003.

40.

En torno a lo politico. Buenos Aires: Fondo de Cultura economica, 2007. p. 15-

O Regresso do Político. Tradução: Ana Cecília Simões. Lisboa: Gradiva, 1996. (Trajectos, 32).

PEREIRA, M. Z. C. Currículo, discurso e discursos. In: MACEDO, Elizabeth; MACEDO, Roberto Sidnei; AMORIM, Antônio Carlos (org.). Discurso, texto, narrativa nas pesquisas em currículo. Campinas - SP: FE/UNICAMP, 2009. p. 114-123.

PEREIRA, M. Z. da C.; ALBINO, A. C. A. Base Nacional Comum Curricular (BNCC): história e precedentes para pensar o Currículo Nacional. In: PEREIRA, Maria Zuleide da Costa; ALBINO, Ângela Cristina Alves (org.). Multifaces da Pesquisa em Educação. 1. ed. João Pessoa: UFPB, 2015. p. 15-38. v. 2.

PEREIRA, M. Z. da C.; LIMA, I. S. (org.). Currículo e políticas educacionais em debate. 1. ed. Campinas, SP: Alínea, 2012. v. 1.258p.

PINA, L. D. "Responsabilidade social” e educação escolar: o projeto de educação básica da "direita para o social" e suas repercussões na política educacional do Brasil contemporâneo. 2016. Tese (Doutorado em Educação) - Faculdade de Educação da Universidade Federal de Juiz de Fora, Juiz de Fora, 2016.

ROCHA, Nathália Fernandes Egito. Base Nacional Comum Curricular e Micropolítica: analisando fios condutores. 2016. 190 f. Dissertação (Mestrado em Educação) Universidade Federal da Paraíba, João Pessoa, 2016.

ROCHA, Nathália Fernandes Egito; PEREIRA, Maria Zuleide da Costa. A prosopopeia da base nacional comum curricular e a participação docente. Horizontes, v. 36, n. 1, p. 49-63, jan./abr. 2018.

O que dizem sobre a BNCC? Produções sobre a Base Nacional Comum Curricular (BNCC) no período de 2010 a 2015. Espaço do currículo, v. 9, n. 2, p. 215-236, maio/ago. 2016.

SOEK, I. C.; MAINARDES, J. Base Nacional Comum Curricular - BNCC: levantamento de publicações (2014-2017). Ponta Grossa: UEPG. Disponível em: <https://www.researchgate.net/profile/Jefferson_Mainardes>. Acesso em: 09 mar. 2019. 
SOEK, Isabelli Cristine. Base nacional comum curricular (BNCC): levantamento de publicações (2014-2017). 2017. 88 f. Trabalho de Conclusão de Curso (Licenciatura em Pedagogia) - Universidade Estadual de Ponta Grossa, Ponta Grossa, 2017

SOUZA, Gessica Mayara de Oliveira. Base Nacional Comum Curricular: análises sobre as influências, disputas e negociações no processo de sua construção. 2017. Trabalho de Conclusão de Curso (Graduação) - Universidade Federal da Paraíba, João Pessoa, 2017.

UNESCO. Declaração mundial sobre educação para todos: satisfação das necessidades básicas de aprendizagem. Jomtien: UNESCO, 1990. 8p.

. Educação para todos: o compromisso de Dakar. Dakar, Senegal: UNESCO, 2000.

Recebido: 05/03/2019

Aceito: 30/03/2019 